International Journal on Applied Bioengineering, Vol.2, No.1, July 2008

\title{
BIOSORPTION OF ACID RED 88 ONTO AZOLLA PINNATA: EQUILIBRIUM AND KINETIC STUDIES
}

\author{
Vijayaraghavan $\mathrm{K}^{1}$ and Padmesh T.V.N. ${ }^{2}$ \\ ${ }^{1}$ Division of Environmental and Chemical Engineering, \\ Research Institute of Industrial Technology, Chonbuk National University, Chonju, South Korea. \\ ${ }^{2}$ Department of Chemical Engineering, Sathaybama University, Chennai, India \\ E-mail: 'padmeshtvn@yahoo.com
}

\begin{abstract}
Azolla pinnata, a fresh water macro alga, was tested for its ability to remove acid red 88 (AR88) from aqueous solution. Batch equilibrium tests at different $\mathrm{pH}$ conditions showed that at $\mathrm{pH} 3$, a maximum AR88 uptake of $55.0 \mathrm{mg} / \mathrm{g}$ was observed according to the Toth model. The ability of $A$. pinnata to biosorb AR88 in a packed column was investigated, as well. The experiments were conducted to study the effect of important design parameters such as bed height flow rate and initial dye concentration. At optimum bed height $(25 \mathrm{~cm})$, flow rate $(5 \mathrm{~mL} / \mathrm{min})$ and initial dye concentration $(100 \mathrm{mg} / \mathrm{L})$, A. pinnata exhibited for AR88. The Thomas model was used to analyze the experimental data and the model parameters were evaluated.
\end{abstract}

KEYWORDS : Azolla pinnata, non linear isotherms, biosorption, packed bed column

\section{INTRODUCTION}

Biological processes such as biosorption [1] bioaccumulation [2] and biodegradation [3] have been proposed as having potential application in removal of dyes from textile wastewater. Among these, biosorption is more advantageous for water treatment because in this process dead organisms are not affected by toxic wastes, they do not require a continuous supply of nutrients and they can be regenerated and reused for many cycles [4]. Biosorption, the passive uptake of pollutants from aqueous solutions by the use of non-living microbial biomass, is a popular technique used for dye removal from wastewaters [5,6]. Some important biosorbents used for dye removal include bacteria [7], fungi [8] and algae [9]. Limited numbers of studies are available on the biological treatment by algal species [5] in spite of their ubiquitous distribution and their central role in the fixation and turnover of carbon and other nutrient elements. However, no research attention has been focused on utilization of macro algae for dye removal. Macro fresh water algae, a renewable natural biomass proliferates ubiquitously and abundantly in the many parts of the world. Azolla, one of the most commonly available fresh water algae, was the focus of the present study. This algae is commonly found in ditches, ponds and slow moving streams and is capable of colonizing rapidly to form dense mats over water surfaces thus imposing negative effects on the aquatic ecology [10].

The present work investigated the dye biosorption behavior of Azolla pinnata on acid red 88 (AR88).

\section{MATERIALS AND METHODS}

\section{A Azolla pinnata}

A. pinnata was collected from Agricultural University, Coimbatore, India. It was then sun dried and crushed to particle sizes in the range of 1 to $2 \mathrm{~mm}$. The crushed particles were then treated with $0.1 \mathrm{M} \mathrm{HCl}$ for $5 \mathrm{~h}$ followed by washing with distilled water and then kept for shaded dry. The resultant biomass was subsequently used in sorption experiments. Acid red 88 was purchased from Sigma-Aldrich Corporation, Bangalore, India.

\section{$B$ Batch experiments}

Batch biosorption experiments were performed in a rotary shaker at $150 \mathrm{rpm}$ using $250 \mathrm{ml}$ Erlenmeyer flasks containing $0.2 \mathrm{~g}$ Azolla biomass in $50 \mathrm{ml}$ of solution containing different acid dye concentrations at desired $\mathrm{pH}$ conditions (using $0.1 \mathrm{M} \mathrm{HCl}$ and $0.1 \mathrm{M} \mathrm{NaOH}$ ). After $12 \mathrm{~h}$, the reaction mixture was centrifuged at $3000 \mathrm{rpm}$ for 10 $\mathrm{min}$. The dye content in the supernatant was determined using UV-Spectrophotometer (Hitachi, Japan) at respective max values $503 \mathrm{~nm}$ for AR88. The amount of dye biosorbed was calculated from the differences between the dye quantity added to the biomass and the dye content of the supernatant using the following equation:

$$
\mathrm{q}_{\mathrm{e}}=\left(\mathrm{C}_{0}-\mathrm{C}_{\mathrm{e}}\right) * \mathrm{~V} / \mathrm{M}
$$

where $\mathrm{q}_{\mathrm{e}}$ is the dye uptake $(\mathrm{mg} / \mathrm{g}) ; \mathrm{C}_{0}$ and $\mathrm{C}_{\mathrm{e}}$ are the initial and equilibrium dye concentrations in the solution $(\mathrm{mg} / \mathrm{L})$, respectively; $V$ is the solution volume $(\mathrm{L})$; and $\mathrm{M}$ is the mass of biosorbent $(\mathrm{g})$.

For kinetic experiments, samples were taken at regular time intervals and analyzed for dye concentration. To evaluate the differences in the biosorption rates and uptakes, the kinetic data were described with Pseudo-first and Pseudo-second order models. The linearized form of Pseudo-first and Pseudo-second order model [6] are shown below as Eqs. (2) and (3), respectively. 


$$
\begin{array}{r}
\log \left(q_{e}-q_{t}\right)=\log \left(q_{e}\right)-\frac{k_{1}}{2.303} t \\
\frac{t}{q_{t}}=\frac{1}{k_{2} q_{e}{ }^{2}}+\frac{1}{q_{e}} t
\end{array}
$$

where $q_{t}$ is the amount of dye sorbed at time $t(\mathrm{mg} / \mathrm{g})$ and $k_{1}$ is the first order rate constant $(1 / \mathrm{min}) ; k_{2}$ is the second order rate constant ( $\mathrm{g} / \mathrm{mg} \mathrm{min}$ ).

\section{CBiosorption isotherm models}

Four equilibrium isotherm models were used to fit the experimental data. These isotherms are the following:

Langmuir: $\quad q=\frac{q_{\max } b C_{f}}{1+b C_{f}}$

Freundlich: $q=K_{F} C_{f}{ }^{1 / n}$

Toth: $\quad q=\frac{q_{\max } b_{T} C_{f}}{\left[1+\left(b_{T} C_{f}\right)^{1 / n_{T}}\right]^{n_{T}}}$

$$
\text { Khan: } q=\frac{q_{\max } b_{K} C_{f}}{\left(1+b_{K} C_{f}\right)^{a_{K}}}
$$

where $q_{\max }$ is the maximum dye uptake $(\mathrm{mg} / \mathrm{g}), b$ is the Langmuir equilibrium constant $(\mathrm{L} / \mathrm{mg}), K_{F}$ is the Freundlich constant $(\mathrm{L} / \mathrm{g}), n$ is the Freundlich constant, $b_{T}$ is the Toth model constant and $n_{T}$ the Toth model exponent; $b_{K}$ is the Khan model constant and $a_{K}$ the Khan model exponent. All the model parameters were evaluated by non-linear regression using MATLAB ${ }^{\circledR}$ software.

\section{$D$ Column experiments}

Continuous flow sorption experiments were conducted in a glass column $(2 \mathrm{~cm}$ internal diameter and $35 \mathrm{~cm}$ height). At the top of the column; an adjustable plunger was attached with a $0.5 \mathrm{~mm}$ stainless sieve. At the bottom of the column, a $0.5 \mathrm{~mm}$ stainless sieve was attached followed by glass wool. A $2 \mathrm{~cm}$ high layer of glass beads ( $1.5 \mathrm{~mm}$ in diameter) was placed at the column base in order to provide a uniform inlet flow of the solution into the column.
A known quantity of $A$. pinnata was packed in the column to yield the desired bed height of the sorbent. Dye solution of known concentration was pumped upward through the column at a desired flow rate by a peristaltic pump (Miclins). The concentration of dye at the vent of the column was collected at regular time intervals.

The breakthrough time $\left(t_{b}\right.$, the time at which dye concentration in the effluent reached $1 \mathrm{mg} / \mathrm{L}$ ) and bed exhaustion time $\left(t_{e}\right.$, the time at which dye concentration in the effluent reached the inlet condition) were used to evaluate the breakthrough curves. The slope of the breakthrough curve $(d c / d t)$ was determined from $t_{b}$ to $t_{e}$. The total quantity of dye mass biosorbed in the column $\left(m_{a d}\right)$ is calculated from the area above the breakthrough curve (outlet dye concentration (C) vs. time (t)) multiplied by the flow rate. Dividing the dye mass $\left(m_{a d}\right)$ by the sorbent mass $(M)$ leads to the uptake capacity (q) of the alga [11]. Effluent volume $\left(V_{\text {eff }}\right)$ can be calculated as follows [12]:

$$
V_{e f f}=F . t_{e} \times \frac{60}{1000}
$$

where $F$ is the volumetric flow rate $(\mathrm{mL} / \mathrm{min})$.

Total amount dye sent to column $\left(m_{\text {total }}\right)$ can be calculated as follows [12]:

$$
m_{\text {total }}=\frac{C_{0} F t_{e}}{1000}
$$

where $C_{0}$ is the inlet dye concentration $(\mathrm{mg} / \mathrm{L})$.

Total dye removal percent with respect to flow volume can be calculated as follows [12]:

$$
\text { Total dye removal }(\%)=\frac{m_{a d}}{m_{\text {total }}} \times 100
$$

All continuous experiments were conducted at room temperature $\left(30^{\circ} \mathrm{C}\right)$.

\section{E. Modeling of column data}

The column biosorption data obtained at different bed heights, flow rates and dye concentrations were fitted using the Thomas model. The linearized form of Thomas model can be expressed as follows (13):

$$
\ln \left(\frac{C_{0}}{C}-1\right)=\frac{k_{T h} Q_{0} M}{F}-\frac{k_{T h} C_{0}}{F} V
$$


where $k_{T h}$ is the Thomas model constant $(\mathrm{L} / \mathrm{mgh}), Q_{0}$ is the maximum solid-phase concentration of solute $(\mathrm{mg} / \mathrm{g}), V$ is the throughput volume $(\mathrm{L})$. The model constants $k_{T h}$ and $Q_{0}$ can be determined from a plot of $\ln \left[\left(C_{d} C\right)-1\right]$ against $t[12]$.

\section{RESULTS AND DISCUSSION}

\section{A. Batch Kinetic studies}

The experimental results of acid red 88 biosorption as a function of time on $A$. pinnata at various initial concentrations have been shown in Fig. 1. For AR 88, biosorption rate was slow and also the equilibrium time attainment increased with increasing dye concentration. On increasing the initial dye concentrations, the total dye uptake increased and the total percent removal decreased. On changing initial AR88 concentrations from 10 to $1000 \mathrm{mg} / \mathrm{L}$, the amount sorbed increased from 1.17 to $45.6 \mathrm{mg} / \mathrm{g}$ at $\mathrm{pH} 3$. But the removal efficiency decreased from 46.8 to $18.2 \%$ as the AR88 concentration increases from 10 to $1000 \mathrm{mg} / \mathrm{L}$.

This is because at lower concentration, the ratio of the initial moles of dye molecules to the available surface area is low and subsequently the fractional sorption becomes independent of initial concentration.

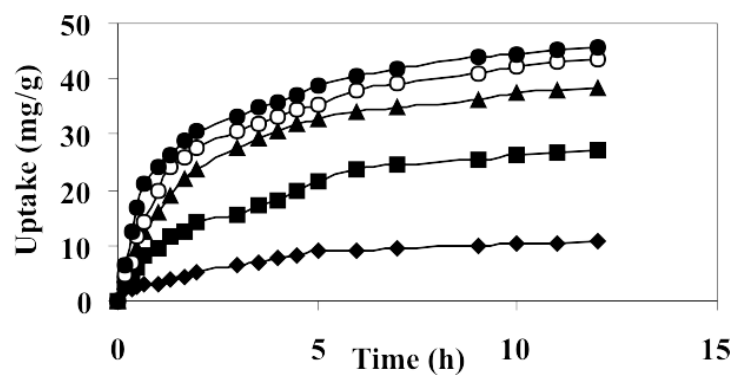

Fig .1 Effect of initial dye concentration on uptake capacity of A. pinnata. Initial dye concentration: ( $) 100 \mathrm{mg} / \mathrm{L}$; ( ) $300 \mathrm{mg} / \mathrm{L}$; ( ) $500 \mathrm{mg} / \mathrm{L}$; ( ) $700 \mathrm{mg} / \mathrm{L} ;$ ( ) $1000 \mathrm{mg} / \mathrm{L}$

However, at higher concentration the available sites of sorption becomes fewer compared to the moles of dye present and hence the percentage dye removal is dependent upon the initial dye concentration. It can be concluded that the rate of AR88 binding with alga biomass is more at initial stages, which gradually decreases and remains almost constant after an optimum period of 6-7 h.

The rate constants, predicted equilibrium uptakes and the corresponding correlation coefficients for all concentrations tested have been calculated and summarized in Table 1. For AR88, correlation coefficients were found to be above 0.959 , but the calculated $q_{e}$ is not equal to experimental $q_{e}$, suggesting the insufficiency of Pseudo-first-order model to fit the kinetic data for the initial concentrations examined. The reason for these differences in the $q_{e}$ values is that there is a time lag, possibly due to a boundary layer or external resistance controlling at the beginning of the sorption process.

The Pseudo-second order model is based on the sorption capacity on the solid phase. Contrary to other well-established models, it predicts the behavior over the whole range of studies and it is in agreement with the binding mechanism being the rate-controlling step.

Table-1. Pseudo-first Order Model Constants

\begin{tabular}{|c|c|c|c|c|}
\hline $\mathrm{C}_{0}$ & $\left.\mathrm{q}_{\mathrm{e}}\right)_{\text {exp }}$ & \multicolumn{3}{|c|}{ Pseudo-first order } \\
\cline { 3 - 5 }$(\mathrm{mg} / \mathrm{L})$ & $(\mathrm{mg} / \mathrm{g})$ & $\mathrm{k}_{1}$ & $\mathrm{q}_{\mathrm{e}}$ & $\mathrm{R}^{2 \dagger}$ \\
& & $(1 / \mathrm{min})$ & $(\mathrm{mg} / \mathrm{g})$ & \\
\hline 100 & 10.6 & 0.338 & 10.5 & 0.971 \\
\hline 300 & 27.2 & 0.363 & 48.7 & 0.964 \\
\hline 500 & 38.3 & 0.359 & 33.7 & 0.980 \\
\hline 700 & 43.6 & 0.344 & 38.3 & 0.959 \\
\hline 1000 & 45.8 & 0.374 & 38.3 & 0.961 \\
\hline
\end{tabular}

This was consistent with the better results obtained with the Pseudo-second order model (Table 2). Correlation coefficients were always greater than 0.992 and the lowest correlation coefficient in this case was better than the first order model correlation coefficients. The values of predicted equilibrium sorption capacities showed good agreement with the experimental equilibrium uptake values.

\section{B. Batch studies}

Experimental AR88 biosorption isotherms for $A$. pinnata at different $\mathrm{pH}$ conditions (2-5) and temperature $\left(25-35^{\circ} \mathrm{C}\right)$ are presented in Fig. 2. Initial solution $\mathrm{pH}$ played a relatively significant role in dye biosorption, with maximum AR88 biosorption observed at pH 3. A slightly decreased AR88 biosorption at other $\mathrm{pH}$ values may be due to nature of binding groups present in the alga. 
Table-2. Pseudo-second Order Model Constants

\begin{tabular}{|c|c|c|c|l|}
\hline $\mathrm{C}_{0}$ & $\left(\mathrm{q}_{\mathrm{e}}\right)_{\exp }$ & \multicolumn{3}{|c|}{ Pseudo-second order } \\
\cline { 3 - 5 }$(\mathrm{mg} / \mathrm{L})$ & $(\mathrm{mg} / \mathrm{g})$ & $\mathrm{k}_{2}$ & $\mathrm{q}_{\mathrm{e}}$ & $\mathrm{R}^{2}$ \\
& & $(\mathrm{~g} / \mathrm{mg} \mathrm{min})$ & $(\mathrm{mg} / \mathrm{g})$ & \\
\hline 100 & 10.6 & 0.022 & 13.7 & 0.994 \\
\hline 300 & 27.2 & 0.010 & 34.1 & 0.992 \\
\hline 500 & 38.3 & 0.014 & 43.5 & 0.999 \\
\hline 700 & 43.6 & 0.012 & 49.0 & 0.998 \\
\hline 1000 & 45.8 & 0.017 & 49.5 & 0.997 \\
\hline
\end{tabular}

The temperature affected the AR88 biosorption capacity of $A$. pinnata. Among the temperature conditions examined, room temperature $\left(30^{\circ} \mathrm{C}\right)$ favored biosorption. Changing the temperature by $\pm 5^{\circ} \mathrm{C}$ from the room temperature resulted in decreased AR88 biosorption capacity.

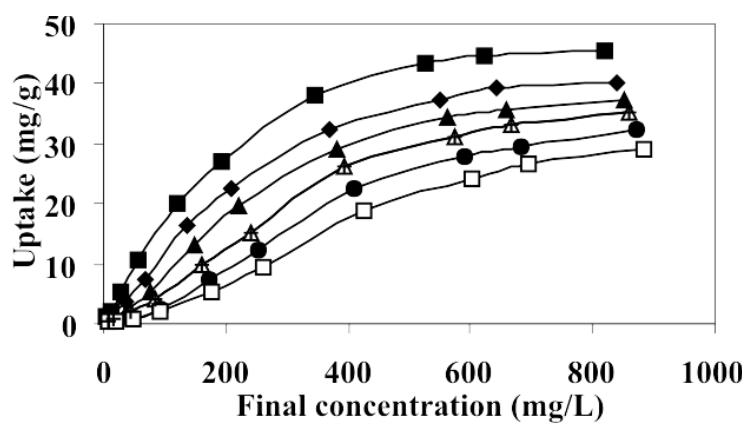

Fig .2 Biosorption isotherms of AR88 for A. pinnata at different conditions (biomass dosage $=4 \mathrm{~g} / \mathrm{l}$ and agitation rate $=150 \mathrm{rpm}$ ). $\mathrm{pH}$ and temperature: () 2 and $30^{\circ} \mathrm{C}$; ( ) 3 and $30^{\circ} \mathrm{C}$; ( ) 4 and $30^{\circ} \mathrm{C}$; () 5 and $30^{\circ} \mathrm{C}$; (+) 3 and $25^{\circ} \mathrm{C}$; ( ) 3 and $35^{\circ} \mathrm{C}$; ( ) 3 and $40^{\circ} \mathrm{C}$; respectively

Langmuir, Freundlich, Toth and Khan models were used to describe the non-linear equilibrium between the sorbed AR88 on the alga (q) and AR88 in the solution $\left(\mathrm{C}_{\mathrm{f}}\right)$. The main reason for extended use of these isotherm models is that they incorporate constants that are easily interpretable. Langmuir sorption model served to estimate the maximum dye uptake values where they could not be reached in the experiments. Table 3. - shows maximum AR88 uptake of $53.76 \mathrm{mg} / \mathrm{g}$ was obtained at optimum $\mathrm{pH}$ (3) and temperature $\left(30^{\circ} \mathrm{C}\right)$
Table-3. Langmuir Model Parameters At Different pH Conditions

\begin{tabular}{|c|c|c|c|c|}
\hline \multirow{2}{*}{$\begin{array}{c}\text { Temp } \\
\left({ }^{\circ} \mathrm{C}\right)\end{array}$} & $\mathrm{pH}$ & \multicolumn{3}{|c|}{ Langmuir model } \\
\cline { 3 - 5 } & & $\begin{array}{c}\mathrm{Q}_{\max } \\
(\mathrm{mg} / \mathrm{g})\end{array}$ & $\mathrm{b}$ & $\mathrm{R}^{2}$ \\
$(\mathrm{~L} / \mathrm{mg})$ & \\
\hline 30 & 2.0 & 50.76 & 0.003 & 0.998 \\
\hline 30 & 3.0 & 53.76 & 0.004 & 0.995 \\
\hline 30 & 4.0 & 45.87 & 0.002 & 0.993 \\
\hline 30 & 5.0 & 42.02 & 0.001 & 0.990 \\
\hline 25 & 3.0 & 42.02 & 0.001 & 0.990 \\
\hline 35 & 3.0 & 37.04 & 0.001 & 0.996 \\
\hline 40 & 3.0 & 36.36 & 0.001 & 0.993 \\
\hline
\end{tabular}

To a lesser extent, the Freundlich model also described the equilibrium data. Both Freundlich constants $(K$ and $1 / n)$ also reached their maximum values at $\mathrm{pH}=3.0$ and temperature $=30^{\circ} \mathrm{C}$ (Table 4$)$.

Table-4. Freundlich Model Parameters At Different pH Conditions

\begin{tabular}{|c|c|c|c|c|}
\hline Temp & \multirow{2}{*}{$\mathrm{pH}$} & \multicolumn{3}{|c|}{ Freundlich model } \\
\cline { 3 - 5 }$\left({ }^{\circ} \mathrm{C}\right)$ & & $\begin{array}{c}\mathrm{K}_{\mathrm{F}} \\
(\mathrm{L} / \mathrm{g})\end{array}$ & $\mathrm{n}$ & $\mathrm{R}^{2}$ \\
& & & & \\
\hline 30 & 2.0 & 0.330 & 1.20 & 0.989 \\
\hline 30 & 3.0 & 0.483 & 1.26 & 0.970 \\
\hline 30 & 4.0 & 0.304 & 1.20 & 0.985 \\
\hline 30 & 5.0 & 0.220 & 1.15 & 0.982 \\
\hline 25 & 3.0 & 0.220 & 1.14 & 0.963 \\
\hline 35 & 3.0 & 0.174 & 1.11 & 0.972 \\
\hline 40 & 3.0 & 0.155 & 1.10 & 0.974 \\
\hline
\end{tabular}

In the case of Toth model, the maximum uptake was obtained in $\mathrm{pH} 3$ and $30^{\circ} \mathrm{C}$. The other two constants $b_{T}$ and $n_{T}$ were also maximum at $\mathrm{pH} 3$ and at temperature $30 \mathrm{C}$. The correlation coefficients in the range of 0.995 to 0.999 were obtained and the model parameters varied with the 
conditions examined. The model reasonably fits the equilibrium data at all conditions examined. According to the Khan model constant, $\mathrm{q}_{\max }$ observed were maximum at the optimum condition ( $\mathrm{pH} 3.0$ and $\left.30^{\circ} \mathrm{C}\right)$, whereas other two constants $\left(b_{k}\right.$ and $\left.a_{k}\right)$ lowest at this condition (Table 6 ). A typical example of batch sorption isotherm fitted using four examined models is shown in Fig .3.

\section{Column studies}

Biosorption of AR88 by A. pinnata was presented in the form of breakthrough curves.

\section{Table-5. Toth model parameters at} different $\mathrm{pH}$ conditions

\begin{tabular}{|c|c|c|c|c|c|}
\hline Temp & $\mathrm{pH}$ & \multicolumn{5}{|c|}{ Toth model } \\
\cline { 3 - 6 }$\left({ }^{\circ} \mathrm{C}\right)$ & & $\begin{array}{c}\mathrm{q}_{\max } \\
(\mathrm{mg} / \mathrm{g})\end{array}$ & $\mathrm{b}_{T}$ & $\mathrm{n}_{T}$ & $\mathrm{R}^{2}$ \\
\hline 30 & 2.0 & 52.5 & 0.002 & 0.697 & 0.995 \\
\hline 30 & 3.0 & 55.0 & 0.004 & 0.770 & 0.999 \\
\hline 30 & 4.0 & 49.2 & 0.003 & 0.698 & 0.995 \\
\hline 30 & 5.0 & 47.6 & 0.002 & 0.564 & 0.996 \\
\hline 25 & 3.0 & 48.5 & 0.003 & 0.745 & 0.997 \\
\hline 35 & 3.0 & 46.2 & 0.002 & 0.689 & 0.998 \\
\hline 40 & 3.0 & 45.9 & 0.002 & 0.623 & 0.995 \\
\hline
\end{tabular}

Fig .4 shows the breakthrough profile of AR88 biosorption for different bed heights $(15,20$ and $25 \mathrm{~cm})$. In order to yield different bed heights, 4.52, 6.14 and $7.89 \mathrm{~g}$ of biomass were added to produce 15,20 and $25 \mathrm{~cm}$, respectively

Table-6. Khan model parameters at different $\mathrm{pH}$ conditions

\begin{tabular}{|c|c|c|c|c|c|}
\hline Temp & pH & \multicolumn{4}{|c|}{ Khan model } \\
\cline { 3 - 6 } & & $\begin{array}{c}\left.{ }^{\circ} \mathrm{C}\right) \\
(\mathrm{mg} / \mathrm{g})\end{array}$ & $\mathrm{b}_{\mathrm{k}}$ & $\mathrm{a}_{\mathrm{K}}$ & $\mathrm{R}^{2}$ \\
\hline 30 & 2.0 & 45.2 & 0.003 & 0.789 & 0.962 \\
\hline 30 & 3.0 & 48.0 & 0.005 & 0.802 & 0.987 \\
\hline 30 & 4.0 & 46.5 & 0.003 & 0.854 & 0.965 \\
\hline 30 & 5.0 & 44.2 & 0.002 & 0.792 & 0.956 \\
\hline 25 & 3.0 & 46.2 & 0.004 & 0.812 & 0.987 \\
\hline 35 & 3.0 & 44.7 & 0.003 & 0.645 & 0.968 \\
\hline 40 & 3.0 & 42.3 & 0.002 & 0.689 & 0.979 \\
\hline
\end{tabular}

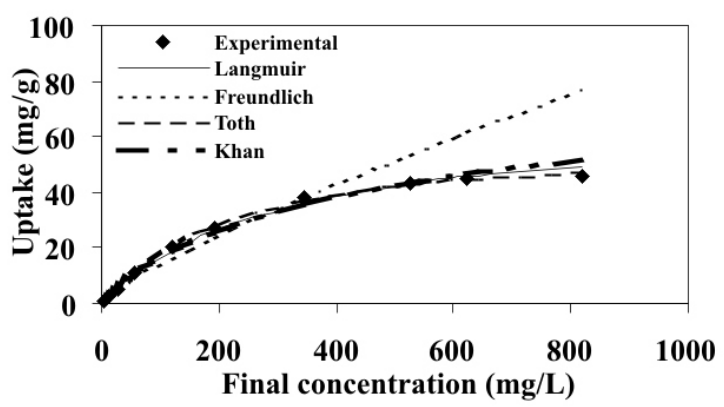

Fig .3. Application of isotherm models to experimental isotherm data obtained during AR88 biosorption by A. pinnata $\left(\mathrm{pH}=3\right.$, tempera ture $=30^{\circ} \mathrm{C}$, agitation rate $=150 \mathrm{rpm}$, biosorbent dosage $=4 \mathrm{~g} / \mathrm{l})$.

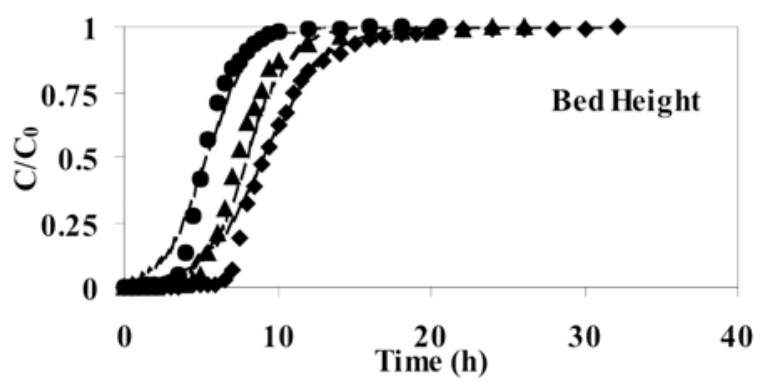

Fig .4. Breakthrough curves for AR88 biosorption onto A. pinnata biomass at different bed heights (flow rate $=5 \mathrm{~mL} / \mathrm{min}$, initial AR88 concentration $=100$ mg/L, pH = 3). Bed heights: ( ) $15 \mathrm{~cm}$; ( ) $20 \mathrm{~cm}$; ( $) 25 \mathrm{~cm}$. (-----) Predicted from Thomas model.

Fig .5 shows the influence of flow rate on biosorption of AR88 by $A$. pinnata by keeping initial dye concentration $(100 \mathrm{mg} / \mathrm{L})$ and bed height $(25 \mathrm{~cm})$ constant and varying the flow rate from 5 to $15 \mathrm{~mL} / \mathrm{min}$. In contrast to bed height results, the column performed well at lowest flow rate. Earlier breakthrough time appeared for highest flow rate, resulting in low uptake and least $\%$ removal. This behavior may be due to insufficient time for the solute inside the column and the diffusion limitations of the solute into the pores of the sorbent at higher flow rates [14].

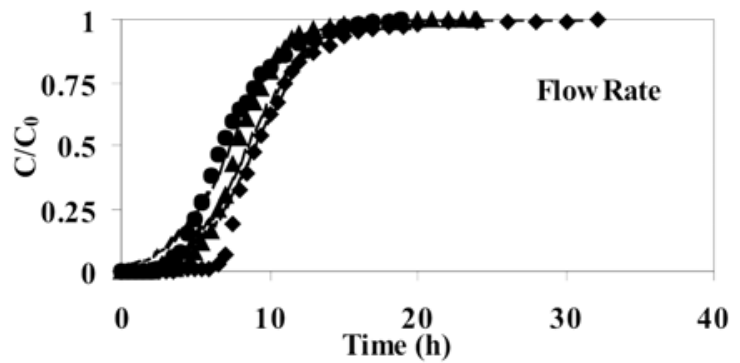

Fig .5. Breakthrough curves for AR88 biosorption onto $A$. pinnata biomass at different flow rates (bed height $=25 \mathrm{~cm}$, initial $A R 88$ concentration $=100$ mg/L, pH = 3). Flow rates: ( $\$$ mL/min; ( ) $10 \mathrm{~mL} / \mathrm{min}$; ( ) $15 \mathrm{~mL} / \mathrm{min}$. (-----) Predicted from Thomas model.

The breakthrough curves obtained by changing AR88 concentration from 50 to $100 \mathrm{mg} / \mathrm{L}$ at $5 \mathrm{~mL} / \mathrm{min}$ flow rate and $25 \mathrm{~cm}$ bed height are shown in Fig .6. At the highest AR88 concentration (100 $\mathrm{mg} / \mathrm{L})$ the Azolla bed saturated quickly leading to earlier breakthrough and exhaustion 
time. Fig .6, shows that highest uptake and high percentage dye removal are obtained at the highest dye concentration. Also more positive and steep breakthrough curve was obtained for $100 \mathrm{mg}$ dye/L. The driving force for biosorption is the concentration difference between the dye on the biosorbent and the dye in the solution [22]. Thus the high driving force due to the high AR88 concentration resulted in better column performance. Comparison of experimentally determined and Thomas model predicted breakthrough curves are shown in Figs. 4, 5 and 6 . As bed height increased, the values of $Q_{0}$ increased and the values of $k_{T h}$ decreased. The bed capacity $Q_{0}$ decreased and Thomas constant $k_{T h}$ increased with increasing flow rate. In general, good fits were obtained in all cases with correlation coefficients ranging from 0.992 to 0.999 for AR88.

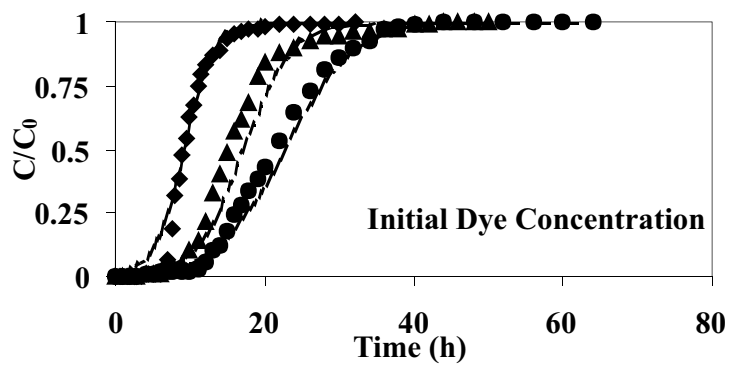

Fig .6 Breakthrough curves for AR88 biosorption onto A. pinnata biomass at different dye concentrations (bed height $=25 \mathrm{~cm}$, flow rate $=5 \mathrm{~mL} / \mathrm{min}, \mathrm{pH}=$ 3). Initial AR88 concentrations: ( ) 50 mg/L; ( ) 75 mg/L; ( $) 100$ mg/L. (-----) Predicted from Thomas model.

\section{SUMMARY AND CONCLUSION}

The present study investigated the following features of dye biosorption on deactivated macro blue green fresh water alga $A$. pinnata in a batch reactor and in a packed bed column. Batch experiments provided fundamental information regarding optimum $\mathrm{pH}$ and maximum dye uptake. Langmuir and Toth model isotherms fit well with experimental data. Column experiments were performed in a packed column, as it makes the best use of the concentration difference known to be a driving force for adsorption. Thus, A. pinnata possesses all intrinsic characteristics to be employed for the treatment of Acid red 88 bearing industrial effluents.

\section{REFERENCES}

[1] K.R. Ramakrishna and T. Viraraghavan, Dye removal using low cost adsorbents. Wat. Sci. Tech., 36 (1997) 189-196.

[2] Z. Aksu, Reactive dye bioaccumulation by Saccharomyces cerevisiae. Proc. Biochem., 38 (2003) 1437-1444.
[3] W.L. Chao and S.L. Lee, Decolorization of azo dyes by three white rot fungi: influence of carbon source. World J. Microbial. Biotechnol., 10 (1994) 556-559.

[4] R.H.S.F. Vieira, B. Volesky, Biosorption: a solution to pollution , Int. Microbial., 3 (2000) 17-24.

[5] S. Venkatamohan, N. chandrasekhar Rao Y, K. Krishna prasad and J. Karthikeyan, Treatment of stimulated reactive yellow 22 (azo) dye effluents using spirogyra species. Waste management, 22 (2002) 575-582.

[6] Z. Aksu, Application of biosorption for the removal of organic pollutants a review. Proc. Biochem., 40 (2004) 997-1026.

[7] T.L. Hu, Removal of reactive dyes from aqueous solution by different bacterial genera. Wat. Sci. Technol., 34 (1996) 89-95.

[8] Y. Fu and T. Viraraghavan, Removal of C.I. acid blue 29 from an aqueous solution by Aspergillus niger. AATCC Mag., 1 (2001) 36-40.

[9] Z. Aksu, and S. Tezer, Biosorption of reactive dyes on the green alga Chlorella vulgaris. Proc. Biochem., 40 (2005) 1347-1361.

[10] T.V.N. Padmesh, K. Vijayaraghavan, G. Sekaran and M. Velan, Batch and column studies on biosorption of acid dyes on fresh water macro alga Azolla filiculoides. J. Hazard. Mat., 125 (2005) 121-129.

[11] B. Volesky, J. Weber, J.M. Park, Continuous-flow metal biosorption in a regenerable Sargassum column, Wat. Res., 37 (2003) 297-306.

[12] Z. Aksu, F. Gonen, Biosorption of phenol by immobilized activated sludge in a continuous packed bed: prediction of breakthrough curves, Proc. Biochem., 39 (2003) 599-613.

[13] G. Yan and T. Viraraghavan, Heavy metal removal in a biosorption column by immobilized $M$. rouxii biomass. Biores. Technol., 78 (2001) 243-249.

[14] DCK. Ko, JF. Porter and G. McKay, Optimised correlations for the fixed-bed adsorption of metal ions on bone char. Chem. Eng. Sci., 55 (2000) 58195829.

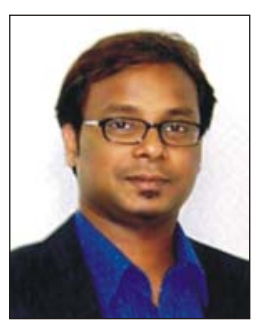

$\mathrm{Dr} \quad \mathrm{K}$ Vijayaragavan is Post Doctorate in Environmental Biotechnology from Chonbuk National University, South Korea. He is currently working for National University of Singapore in the Department of Environmental Science and Engineering. His contributions in the field of

Environmental Biotechnology is immense. 